\title{
Philosophiques
}

\section{Index volume XXIV — 1997}

Volume 25, numéro 1, printemps 1998

URI : https://id.erudit.org/iderudit/027483ar

DOI : https://doi.org/10.7202/027483ar

Aller au sommaire du numéro

Éditeur(s)

Société de philosophie du Québec

ISSN

0316-2923 (imprimé)

1492-1391 (numérique)

Découvrir la revue

Citer ce document

(1998). Index volume XXIV - 1997. Philosophiques, 25(1), 145-147.

https://doi.org/10.7202/027483ar

Ce document est protégé par la loi sur le droit d'auteur. L'utilisation des services d'Érudit (y compris la reproduction) est assujettie à sa politique d'utilisation que vous pouvez consulter en ligne.

https://apropos.erudit.org/fr/usagers/politique-dutilisation/
Cet article est diffusé et préservé par Érudit.

Érudit est un consortium interuniversitaire sans but lucratif composé de l'Université de Montréal, l'Université Laval et l'Université du Québec à Montréal. Il a pour mission la promotion et la valorisation de la recherche. https://www.erudit.org/fr/ 


\section{INDEX \\ VOLUME XXIV - 1997}

Numéro 1 (Printemps) :

Numéro 2 (Automne) :

ARTICLES

Jean-Paul Brodeur, Justice distributive et justice rétributive

Charles Coutel, De Thomas More à Condorcet: une relève du discours utopique?

Jocelyne Couture, L institutionnalisation de la raison publique. le moral et le polinique

Christian Godin, Tensions et apories de l'encyclopédisme

Laurent-Paul Luc, Vie et vie pensante dans le Systemfragment que Hegel rédigea lors de son séjour à Francfort

Éric Méchoulan, Du bon usage de la haine et du respect dans les Pensées de Pascal

Bjarne Melkevik, Présentation du numéro thématique .............................. 3

Bjarne Melkevik, Du contrat à la communication :

Habermas critique Rawls

Aloyse-Raymond Ndiayć, Le corps-machine et le srai homme. La controserse entre Arnauld et M. Le Moine, doyen de Vitré

Kai Nielsen, Après Rawls : la notion de raisonnable comme outil critique

Geneviève Nootens, La nature de la complémentarité 'nure le raisonnable el le rationnel chez Rawls

Paule-Monique Vernes, Les Passions de l'âme de Descarres les limites d'un type d'explication

\section{INTERVENTIONS}

Jacques Bouet, La définition de la simultanéité pour des corps en mouvements rectilignes et pour ceux en mouvements circulaires

Michel Guérin, Le concept de topoiétique

Charles Larmore, L autonomie de la morale

COMMENTAIRES

Jocelyne Couture, À quoi servent les faits normatifs?

Lukas K. Sosoe, Autonomie de la morale ou morale de l'autonomie. 
Georges Leroux, Modernité des Grecs.

L'importance de la pensée grecque et les raisons

de l'enseigner dans le programme collégial de philosophie

Christian Talin, De l'infanticide en Chine au XVIII siècle.

Considérations sur les facteurs sociaux

\section{TABLE RONDE}

Le problème mathématique de l'espace

A propos d'un ouvrage récent de Luciano Boi

Sous la direction de Robert Nadeau

Robert Nadeau, Présentation

Alain Michel, Espace et intelligibilité mathématiques:

sur le problème mathématique de l'espace

Jean Petitot, Philosophie transcendantale et objectivité physique ............ 367

Luciano Boi, La géométrie : clef du réel? Pensée de lespace

et philosophic des mathématiques

\section{ETUDES CRITIQUES}

Gerardo Mosquera,

Yvon Lafrance, Pour interpréter Platon II.

La ligne en République VI, 509d-511e.

Le texte et son histoire

\section{COMPTES RENDUS}

William Baranès et Marie-Anne Frison-Roche, La justice.

L'obligation impossible (Bjarne Melkevik)

Jocelyn Benoist, Kant et les limites de la synthèse.

Le sujet sensible (Claude Piché)

Rudolf Bernet, La vie du sujet. Recherches sur l'interprétation de Husserl dans la phénoménologie (J. Nicolas Kaufmann)

Maurice Blondel, Eusres complètes (vol. 1): 18.93. Les deux thèses (Alain Létourneau)

Josiane Boulad-Ayoub, Mimes et parades. L'activité symbolique dans la vie sociale (Roberto Miguelez)

Gérard Cholvy et Nadine-Josette Clualine (éds), l, enseignement catholique en France aux $X I X^{c}$ et $X X^{r}$ siécless

(Michel Despland)

Yvon Gauthier, La philosophie des sciences

Une introduction critique (Jean Lachapelle)

Pierre Hadot, Plotin : Traité 9 (VI 9) (Georges Leroux)

Gilbert Hottois, De la renaissance à la postmodernité.

Une histoire de la philosophie moderne et contemporaine

(Lazare M. Poamé)

Institut de formation continue du Barreau de Paris, (sous l'égide de) Le doute et le droit (Bjarne Melkevik)

Denis Kambouchner, L'homme des passions (Christian Nadeau) 
François Leroux, Figures de la souveraineté.

Nietzsche et la question politique (Frédérique Doyon)

John Stuart Mill, Essais sur Tocqueville et la société américaine

(Sophie Jankelevitch)

Iygia Négrier-Dormont et Stamatios Tzitzis, Criminologie de l'acte 't philosophic pénale. De l'ontologie criminelle des Anciens

ì la victimologie appliquée des Modernes (Christian Talin)

Marco Panza cl Jean-Michel Salanskis (éds),

Lobjectivité mathematique. Platonisme ot structures formelles.

(Yvon Gauthice)

Gérard Raulel, /listoire et citoyenneté (Maxime Lebeuf) ...................... 437

Nlfied Schmidt, Le concept de nature chez Marr

(Louis Desmeules)

Michel Seymour, Pensée, langage et communauté.

Une perspective anti-individualiste (Don Ross)

I _eo Strauss et Joseph Cropsey, Histoire de la philosophie politique.

Leo Strauss, Qu est-ce que la philosophie politique?

(Pierre Gravel)

Stamatios Tzitzis, La philosophie pénale (Christian Talin) 206

Patrice Vermeren, Victor Cousin.

Le jeu de la Philosophie et de l'État (Michel Despland)

Jean-Louis Vieillard-Baron (éd.), De Saint Thomas à Hegel

(Mylène Dufour) 